\title{
DIE VERLEDE HEDE EN TOEKOMS VAN ISRAEL IN DIE ROMEINEBRIEF
}

\author{
DS. E. ENGELBRECHT.
}

\section{INLEIDING.}

Hierdie studie wil probeer om in die bestek van 'n artikel 'n antwoord op die vraag te gee hoe Paulus die volk Israel in die Romeinebrief sien. Hierdie vraag self speel in die opset en teologie van die Romeinebrief ' $n$ besondere rol, want Paulus behandel die vraag na Israel nie as 'n adendum tot die brief nie, maar as 'n integrale deel.

Vanuit die vraagstelling sal die studie veral eksegese werk wees') wat 'n bydrae wil lewer tot die diskussie rondom Israel. Verskeie vrae rondom Israel het ook in die huidige tyd in die kerk, in ons land en ook in die buiteland redelik sterk op die voorgrond getree.

Die vraagstelling self beperk die ondersoek tot die Romeinebrief en die praktiese oorweging van omvang en tyd wil ook aan die werkstuk 'n eksegetiese karakter gee. Hiermee wil nie gesè word dat Paulus in die Romeinebrief 'n enigste woord oor Israel gespreek het nie. Vanuit die intensiwiteit waarmee Paulus hierdie probleem in die Romeinebrief behandel, sal die Romeinebrief egter ' $n$ besondere rol speel in die uiteindelike sistematisering van die vrae rondom Israel.

\section{DIE VERANKERING VAN ISRAEL IN DIE TEOLOGIESE STRUKTUUR VAN DIE BRIEF.}

Ten eerste is dit opmerklik dat die vraagstuk rondom die Jood en Israel in die Romeinebrief sterk gesistematiseer is. Dit hang onder ander (1) nou saam met die feit, dat Paulus die voortgang van die brief (trouens sy hele teologie) op 'n besondere wyse gaan koppel het aan besondere figure in die ou verbond, naamlik Adam, Abraham en Moses. ${ }^{2}$ ) (2) Dat die Romeinebrief sterk bepaal word deur die tema, "Regverdigmaking deur die geloof", bring ook mee dat die Jood en Israel sterk ter sprake sal moet kom.

\section{Adam.}

Paulus wys op die verwoestende gevolge van die ongehoorsaamheid van Adam vir die hele mensdom. Hierdie gevolge tref die heiden en die Jood. Die uiteinde van hierdie gevolge is dat

1) Die eksegese is deel van die knelpunt in die teologiese diskussie rondom Israel. C. J. Mans, Rondom Kerk van Israel, H.T.S. Jaargang 26, Afl. 1 en 2, bl. 100 .

2) Dit is duidelik aangetoon in die werk van C. K. Barrett, From First Adam to Last, London, 1962. 
deur die "oortreding van die een (dit wil sê Adam) die dood geheers het deur dié een" (Rom. 5:17). Vanuit Adam moet ons die mensdom as 'n eenheid sien. Die oortreding van Adam het 'n oneindige katastrofe oor die mensdom gebring - beter gesê oor elke mens. Die dood het tot elke mens deurgedring (Rom. 5:12). Die begrip oortreding (paraptōma)") (Rom. 5:15 en 17) bring die besonderheid van Adam se skuld na vore: hy het die een gebod wat God gegee het, oortree. Agtergrond van sy oortreding was dat hy ,soos God' wou word. Nou kan 'n mens maklik dink dat die ontsettende gevolge van 'n eenmalige historiese gebeure net dat hy ,soos God' wou word. Nou kan 'n mens maklik dink dat hierdie gevolg in die verlede lê. Die onmiddellikheid van die gevolg in die verlede loop deur tot vandag toe. (diēlthen as ingressiewe auristus). Die sonde en sy gevolge is vir Paulus ook nie 'n ding wat van geslag tot geslag oorhandig word nie.") Die sonde is werklik lewend, aktief, byna persoonlik. Die sonde hoef nie gepropageer te word nie - dit propageer dit self (Rom. 2:21-22). Ook die Jood as mens (Adam) is sonder verontskuldiging, want hy doen ook ,dieselfde dinge' (Rom. 2:1), naamlik die afgodery en ontug van die heiden wat Paulus beskryf in Rom. 1:18-32. Opsommend kan gesê word dat Paulus alles wat van Adam gesê word, van elke mens (ook die Jood) sê. Hy maak ten volle erns met die Hebreeuse woord 'ādām.

Wat die mens - elke mens nodig het, is om in die ware Skepper-skepsel verhouding herstel te word. Die mens moet van sy verwaandheid afstand doen. Die volheid van die onheil deur die oortreding word egter deur die volheid van die genade oortref en oorwin. As ons die genade van God en die gawe van Jesus Christus met die sonde vergelyk, sal ons moet sê dat die genadegawe veel meer is. ${ }^{5}$ ) (Vgl. Rom. 5:15). Paulus is in Rom. 5:12-21 met ' $n$ antitetiese tipologie besig tussen Adam en Christus. Aan die een kant het ons die oortreding, sonde en dood en aan die ander kant die genade, geregtigheid en die lewe (Rom. 5:17, 19, 21). Soos wat die oortreding van Adam deurgedring het tot baie (Rom. 5:15) ja tot almal - elke mens, (Rom. 5:12), so is die genadegawe veel meer vir baie (Rom. 5:15), ja alle mense tot die lewe (Rom. 5:18). Toe Paulus ten volle erns gemaak het met Adam, is ook die Jood onder die sonde en sy gevolge gestel. As hy ten volle erns maak met die genadegawe van Christus, moet ook die Jood onder die een daad van regverdigmaking gestel

3) Paraptoma wil op 'n konkrete. waarneembare, bepaalde oortreding wys. C. K. Barrett, From First Adam, p. 62.

4) C. K. Barret, From First Adam, p. 20.

5) Perisseuein $3 X$ in Rom. 5:12-21. 
word. Soos wat deur een mens die dood tot alle mense deurgedring het, so het deur die Een mens die regverdigheid tot die lewe tot alle mense gekom. Die ware bestaan van alle mense is gelë in die gehoorsaamheid aan Jesus Christus.

Nou is dit so dat die lewe nog nie tot alle mense gekom het nie, maar deur die evangelie is dit besig om tot alle mense te kom. Die eindtydelike deurgaan van die heil na Jood en heiden het in Jesus Christus begin. In Christus is die dood reeds oorwin en gaan hierdie oorwinning na alle mense deur in die voortgesette eskatologiese aktiwiteit van Jesus Christus deur sy evangelie (Rom. 1:16 vlg.). So het die volharding tydelik oor Israel gekom totdat die voltal') (to plērōma) van die heidene ingegaan het (Rom. 11:25). Maar die tyd wat nou aangebreek het in Jesus Christus is die eindtyd - die tyd van Gods genade waarin ook Israel genade sal ontvang (Rom. 11:3). God se barmhartigheid oor die heidene word nou vir God weg tot barmhartigheid oor Israel.i) Paulus se eskatologiese nun moet in die laaste gedeelte van Rom. 11:31 behou word. (hina kai outoi nún eleēthōsin). Die eskatologiese voortgang van die evangelie sal eindelik ook Israel inhaal. Die verkondiging van die evangelie deur die heidenchristene word weg van God om ook aan Israel barmhartigheid te bewys. Die verharding van en die barmhartigheid oor Israel is nou (nun).

As K. Barth ${ }^{8}$ ) hierdie nou uitlê sê hy dat dit nie beteken dat die christene hulle houding teenoor die Jodevraag tot die jongstedag kan uitstel nie, maar dat hulle nou daarvoor verantwoordelik is dat deur die barmhartigheid wat hulle ervaar het ook die Jode barmhartigheid verkry.

Jood en heiden staan slegs teenoor Jesus Christus bymekaar. Hier is hulle onder die ongehoorsaamheid ingesluit. Maar hulle is in Jesus Christus saam in die ongehoorsaamheid ingesluit sodat Jood en heiden aan sy barmhartigheid deel kan kry (Rom. 11:32).

Tot hiertoe is die plek van Israel in die eskatologiese tyd (en veral die kerk se sendingverantwoordelikheid - of eerder sendingvoorreg) rondom die antitetiese tipologie Adam-Christus aangewys.

\section{Abraham.}

Wat is die plek van Israel as ons na Paulus se hantering van Abraham in die Romeinebrief kyk? As ons Paulus se behandeling van Abraham nagaan, kan ons dit met 'n enkele woord opsom:

6) C. K. Barrett. The Epistle to the Romans, London, 1967, p. 221.

¡) E. Gaugler. Der Brief an die Römer. Zürich, 1945, Vol. II, S.209.

8) K. Barth, Kurze Erklärung des Römerbriefes, München, 1956, S.179. 
Abraham het geglo. Deur Abraham as voorbeeld te gebruik, verduidelik Paulus wat geloof is. Die locus classicus is Rom. 4. Die aanloop na Rom. 4 behandel die regverdigheid deur die geloof (Rom. 3:21-31). Ook hier wil Paulus aan die begin (Rom. 3:22-23) dit duidelik stel dat daar (in ' $n$ besondere sin) geen onderskeid tussen Jood en heiden is nie. Dit het hy al herhaaldelik gestel, ook onder andere in Rom. 3:9: „Want ons het tevore al Jode sowel as Grieke beskuldig dat hulle almal onder die sonde is." Die regverdigheid van alle mense deur die geloof sonder die werke van die wet sou by enige Jood die vraag laat ontstaan: Maar wat van Abraham? Vir die Judaĩsme was Abraham die hoogtepunt van vroomheid en deug. ${ }^{9}$ )

Paulus neem Gen. 15:6 as teksvers om Abraham se regverdigheid te beskryf: „Abraham het in God geglo en dit is hom tot geregtigheid gereken." Die episteusen kan egter ook verstaan word (en is deur die Judaïsme só verstaan) as vroom en opreg wees in jou handel en wandel. Abraham het die versoeking só weerstaan dat God nie anders kon as om hom regverdig te reken nie.

Paulus eksegetiseer Gen. 15:6 egter nie as 'n werkgeregtigheid nie, maar as geregtigheid deur die geloof. Om die betekenis van episteusen te bepaal, dek Paulus die tora deur 'n psalmwoord. Die woord elogisthē laat Paulus Ps. 32:1 aanhaal. Hierdie parallelle gedeelte toon aan dat die mens regverdig word deur die feit dat God die ongeregtigheid vergewe en die sonde nie tosreken nie, en dat dit nie daarin bestaan dat goeie werke erken word nie. Nou toon Paulus aan dat hierdie ,nie toereken nie' en die ,vergewe' daad van God was toe Abraham nog onbesnede was. Geloof is dus ' $n$ verhouding tot God buite die wet. Ook die belofte dat hy erfgenaam van die wêreld sou wees, het hy buite die wet ontvang deur die geregtigheid van die geloof (Rom. 4:13). In Rom. 4:10-12 stel Paulus dat die besnydenis slegs teken is van dit waarheen dit heenwys, naamlik die geregtigheid uit die geloof. Die geregtigheid uit die geloof is nie noodwendig en onlosmaaklik aan die besnydenis verbonde nie. Die besnydenis is uiterlike teken (sēmeion) en dit verseël 'n geloofsinhoud. Hierdie uiterlike teken bewerk nie die regverdigheid nie. Abraham se besnydenis en sy geloof is parallel: beide sy geloof en besnydenis was geen daad van menslike prestasie nie.

Die belofte wat Abraham in die geloof ontvang het, was dat „In jou saad sal al die nasies van die aarde geseën word” (Gen. 22:18). Aan hierdie belofte het die Jode geen aandag gegee nie, of so nie dit heeltemal afgeswak. ${ }^{10}$ ) Die kindskap van Abraham

9) C. K. Barrett, From First Adam, p. 31.

10) C. K. Barrett, From First Adam, p. 34 en 40. 
word nie deur die besnydenis bepaal nie, maar deur die geloof. Abraham is „Vader van die besnydenis vir die wat nie alleen op die besnydenis vertrou nie, ${ }^{11}$ ) ja inderdaad ${ }^{12}$ ) vir die wat in die voetstappe volg van die geloof van ons vader Abraham toe hy onbesnede was" (Rom. 4:12). So moet ook Rom. 2:29 verstaan word: Maar hy wat dit in die verborgene is, is 'n Jood, en besnydenis is dié van die hart in die gees, nie na die letter nie ...

Die belangrike is dat ons Abraham se geloof sal deel. Paulus is nie begaan oor die vleeslike kindskap van Abraham nie. Die Jood kan inderdaad Abraham se kind wees as hy bo en behalwe dat hy Abraham se bloed in sy are het en besny is, ook nog volg in die voetstappe van Abraham se geloof. Hy wat aan Christus behoort is kind van Abraham. Die term Israel moet dus nie slegs verstaan word as 'n bloedlyn nie.

... Want hulle is nie almal Israel wat uit Israel is nie. Ook nie omdat hulle Abraham se nageslag is, is hulle almal kinders nie (Rom. 9:6-7).

Die kinders van die belofte is waarlik kinders (Rom. 9:8). 'n Tweede faktor wat Israel naas die belofte bepaal, is die verkiesing (Rom. 9:11) en roeping van God, (ouk eks ergōn all' ek tou kalountos). Van hieruit moet ook die klētos apostolos en die kletois hagiois van Rom. 1 verstaan word. Ons moet dus onderskei tussen Israel na die vlees en Israel na belofte en roeping. Op die oog af lyk dit of die Jood en die Israeliete alle reg aan hulle kant het. Aan hulle is die woorde van God toevertrou (Rom. 3:2). Aan hulle behoort die heerlikheid en die verbonde en die wetgewing en die beloftes en die Vaders en uit hulle is die Christus na die vlees (Rom. 9:4-5). Maar, in der waarheid het Israel in die wet verstrik en verslaaf geword - die ware afstamming van Abraham gaan nie langs die lyn van wet en besnyding nie, maar langs die lyn van God se genade, belofte en roeping in Jesus Christus. Waarom het Israel nie die geregtigheid bereik nie? Omdat hulle dit nie deur die geloof (nagejaag het nie), maar asof hulle dit deur die wet kon bereik (Rom. 9:32). „Want hulle het hulle gestamp teen die steen van aanstoot" (Rom. 9:32). "Want omdat hulle die geregtigheid van God nie ken nie en hulle eie geregtigheid probeer oprig, het hulle hul aan die geregtigheid van God nie onderwerp nie" (Rom. 10:3).

Hiermee het ons gevorder tot by 'n derde uitsig op Israel naamlik vanuit Moses.

11) Ek peritomés monon; vertaling van C. K. Barrett, Romans, p. 86 .

12) Om alia kai adversatief te verstaan is dalk die eenvoudigste oplossing vir die vertaling en verklaring van die vers. Vir die vertalings- en verklaringsprobleme 0 . Michel. An die Römer, S.120. C. K. Barrett wil tois voor stoichousin laat wegval. So ook die Afrikaanse vertaling. 


\section{Moses.}

Moses is ook vir Paulus 'n primêre outoriteit. Daarom kan hy sê: Moses skryf . . . (Rom. 10:5). Met die wet waarvan Moses die bemiddelaar was, was daar geen fout nie. „Dus is die wet heilig en die gebod is heilig en regverdig en goed" (Rom. 7:12). Vgl. ook Rom. 7:14. Die wet het egter die belofte aan Abraham nie vervang nie. „As die wat op die wet vertrou erfgename is, dan het die geloof waardeloos geword en is die beloftes tot niet gemaak" (Rom. 4:14). En tog was die wet kragteloos om te regverdig, dit vanweë die onmag van die mens om die goeie te doen. "Want ons weet dat die wet geestelik is, maar ek is vleeslik, verkoop onder die sonde" (Rom. 7:14). Die wet was kragteloos deur die vlees (Rom. 8:3). Die gevolg van die oortreding van Adam het die wet wat goed was, onmagtig gemaak om die mens tot regverdigheid te lei. Soos wat daar 'n ware en 'n valse Israel, 'n ware en 'n valse besnydenis is, so is daar 'n regverdigheid deur die wet wat nie bereik kan word nie, want „die mens wat dit gedoen het, ${ }^{13}$ ) sal daardeur lewe" (Rom. 10:5). Deur die wet kan die regverdigheid nie bereik word nie, want ,ek is vleeslik, verkoop onder die sonde" (Rom. 7:14). Teenoor hierdie vergeefse regverdigheid staan die regverdigheid deur die geloof. 'n Regverdigheid wat hierin bestaan dat ,.jy met jou mond die Here Jesus bely en met jou hart glo dat God Hom uit die dode opgewek het ..." (Rom. 10:9). Die wet se goedheid lê dus hierin dat dit getuie is van die vrugteloosheid van die wetsregverdigheid, (Rom. 10:5 - wat ' $n$ aanhaling is uit Lev. 18:5) en verkondiging is van die geloofsgeregtigheid (Rom. 10:6 wat 'n aanhaling is uit Deut. 9:4).

As die Jode dus Moses werklik so hoog ag soos wat hulle voorgee, $\left.{ }^{14}\right)$ sal hulle Moses ook navolg, want Moses getuig van die evangelie! Die wet beveel dieselfde verhouding tot God as dié waarin Abraham gestaan het.

Wanneer ons vanaf Christus oor Moses na die Jood kyk, sal ons wet en evangelie só sien, naamlik dat Christus (evangelie) die einde van die wet is (telos nomou Christos, Rom. 10:4). As agtergrond van hierdie uitspraak moet ons vashou dat Paulus Christus verkondig as die krisis van die tyd. Telkens kom ons die eskato. logiese nou (nun) ${ }^{15}$ ) teë. Hierdie nun is kenwoord uit die frase en tō nun kairō. In Jesus Christus is die verhouding wat tussen God en die mense geheers het, afgesluit. ${ }^{16}$ ) 'n Nuwe tyd - 'n nuwe

13) Poiesas our! part. Die auristus dra hier 'n effektiewe krag.

14) Die hoogskatting en oorskatting van Moses is aangetoon deur $C$. K. Barrett, From First Adam, p. 59.

15) 18 Keer.

15) Onder „Eksegetiese vrae ..." sal op nun nader ingegaan word (III, 1). 
verhouding het nou tussen God en sy mense aangebreek. In Christus word nou die mens se verhouding tot God bepaal en daarom is Hy ook die einde van die wet. As ons telos (Rom. 10:4) ook verstaan as doel naas einde, dan het die wet sy doel in Christus bereik - die wet se doel is in Christus vervul. As die Jood die wet dus ten volle ernstig neem en die geregtigheid nastreef, sal hy Christus omhels.

\section{ENKELE EKSEGETIESE VRAE RONDOM ISRAEL.}

\section{Nou (Nun).}

Die gebruik van nun deur Paulus wil veral aandui dat in Jesus Christus die krisis van alle mense aangebreek het.

Teenoor 'n voorafgaande tyd waarin God die sonde laat verbygaan het (paresis) in sy verdraagsaamheid, het die tyd waarin God se geregtigheid openbaar is (endeiksis), nou aangebreek (Rom. 3:25, 26). In Jesus Christus het die tyd van God se geregtigheid aangebreek (Rom. 3:21). Omdat die huidige tyd die tyd van die openbaring van God se geregtigheid is, is dit ook die tyd waarin God die wat in Jesus Christus is, regverdig maak. Die huidige tyd is die tyd waarin die gelowiges geregverdig is deur die bloed van Jesus Christus (Rom. 5:9). Hierom is dit nou ook die tyd van die versoening (katallagè, Rom. 5:11) deur Jesus Christus.

Teenoor 'n eens (tote), staan 'n nou (nun, Rom. 6:21). Teenoor ons oue mens (palaios hēmōn anthrōpos) wat saam met Christus gesterf het (Rom. 6:6, 7, 8), staan nou 'n mens wat lewend is vir God in Christus Jesus (Rom. 6:11). Die mens wat deur Jesus Chris. tus lewend is, dien die sonde nie meer nie (Rom. 6:6), en is "nou ontslae van die wet waardeur ons gebonde was" (Rom. 7:6). Nou is die tyd waarin daar geen veroordeling is vir die wat in Jesus Christus is nie (Rom. 8:1). Nou is die tyd van God se barmhartigheid (Rom. 11:30).

God het nou in Christus aan die geskiedenis 'n wending gegee. Die gevolge van hierdie wending loop tot aan die einde toe deur. Hierdie wending deur Jesus Christus is krisisoomblik vir elke mens: daar moet vir of teen Christus gekies word. Nun is 'n periode met ewigheidsgewig, ${ }^{1 i}$ ) die eskatologiese teenwoordigheid - tyd van vervulling en verwagting ${ }^{18}$ ) op grond van die vervulling. Die tyd van God se geregtigheid en barmhartigheid is die tyd van die oorblyfsel (leimma, Rom. 11:5) uit Israel en ook die tyd waarin Israel (saam met die heidene) nog barmhartigheid sal ontvang (Rom. 11:31-32).

17) T.W. N.T. IV., S. 1107. (Stählin).

18) G. Delling, Das Zeitverstandnis des N.T., 1940, S. 101. 
Die nou het dus ook sy skadukant. Die skepping sug en is in barensnood (Rom. 8:22), en Israel het nog nie almal barmhartigheid ontvang nie. Hierdie skadukant bring dus mee dat die teenwoordige tyd ook tyd van verwagting is. Maar hierdie verwagting is nie veraf of onbepaald nie. Hierdie verwagting in die teenwoordige tyd is bepaal deur die geregtigheid en barmhartigheid van God wat in Jesus Christus openbaar is. Hierdie periode is dus begrens deur die twee markantste punte in die wêreldgeskiedenis, die begin en die afsluiting van die komende godsryk..$^{19}$ ) Teken en brenger van die begin en einde is Jesus Christus self.

Die nuwe van die verhouding tot God lê hierin dat die mens (ook die Jood) se lewe nou nie meer in slawerny van die sonde verloop nie (Rom. 6:20), nie meer onder die dwangjuk van die wet is nie (Rom. 7:1 en 6), maar nou verloop in geregtigheid, (God se geregtigheid!, Rom. 3:21), vryheid (Rom. 6:22) en die vernuwing deur die Gees (Rom. 7:6). - Hierdie nuwe verhouding is opvallend in die lewe van die heiden-christen, maar net so wonderlik in die lewe van Jode-christen (Rom. 6:21 vgl., 8:1) ${ }^{21}$ ) 2. Judaiō te prōton kai Hellēni (Rom. 1:16).

Waarom het die Jood voorrang en waarin bestaan sy voorrang? Die "evangelie is 'n krag van God tot redding vir elkeen wat glo" (Rom. 1:16), maar in hierdie "vir elkeen" is 'n rang. orde - eerste vir die Jood. (a) Hierdie eerste is egter nie 'n eerste wat nou eers te voorskyn getree het nie. Die evangelie kom nie nou eers tot die Jood nie, maar is lank tevore deur die profete aan Israel vooraf aangekondig. Hierdie voorrang is dus nie aan 'n menslike kwaliteit of omstandigheid gebonde nie, maar aan die kontinuiteit van Gods belofte. Die evangelie van Jesus Christus is nie 'n opheffing van die vroeëre belofte van God nie, maar bevestiging daarvan (Rom. 1:2). Hierom spreek die evangelie van Jesus Christus eerste tot die Jood, want dit is dieselfde evangelie wat nog tot hom spreek. ${ }^{21}$ ) (b) Eers vir die Jood en ook vir die Griek is nie bloot uitdrukking van 'n sendingsmetode van Paulus nie, maar uitdrukking van dié verborgendheid dat deur die struikeling van Israel die saligheid tot die heidene gekom het (Rom. 11:11). Judaiō te prōton kan dus nooit alleen staan nie. maar moet altyd saamgelees word met kai Hellēni. Daarom praat die nuwere eksegete eerder van 'n ,historiese voorsprong' (A. Julicher, M. J. Lagrange, K. Barth) as van 'n voorrang. As ons hierdie ,eers aan die Jood en ook aan die Griek" altyd bymekaar

19) G. Delling, Das Zeitverständnis des N.T., S. 126.

20) T.W.N.T. IV., S. 1111.

21) Hierop wys veral A. Schlätter, Gottes Gerechtigkeit,: Stuttgart 1965, S. $33 / 34$. 
sien en die voorrang van die Jood sien as die kontinuîteit van die evangelie wat hierin bestaan dat die belofte wat eerste aan die Jood gemaak is en daarom ook eerste aan hom verkondig word, dan kan hierdie voortgaan en deurgaan na die Griek nie gesien word as 'n ,easy going diarity":-z) nie, maar as die voortgaan en deurgaan van die genade van God. Ons het hier dus nie alleen te doen met 'n voorsprong in die tyd nie, maar met 'n (soos O. Michel dit stel) „heilsgeschichtliche Notwendigkeit". ${ }^{23}$ ) (c) Hierdie voorrang wat in die voortgaan van die evangelie lê, hou vir Israel egter ook 'n verdere saak in. Nie alleen die sōteria (Rom. 16:1) en eirēnē (Rom. 2:10) bereik hom eerste nie, maar juis daarom ook die "verdrukking en benoudheid" (Rom. 2:9), want hy het die evangelie wat eerste na hom gekom het, verwerp. Maar omdat teenoor die genade van God in Jesus Christus Jood en heiden bymekaar hoort, gaan die evangelie nie slegs voort nie, maak ook na die heiden deur. Hierom is die „verdrukking en benoudheid" wel eers vir die Jood maar ook vir die Griek wat die kwaad doen. (d) Jodendom en kerk staan dus nie sondermeer parallel langs mekaar nie. Daar is wel 'n verband, maar die verband is die evangelie. Tussen hulle is dus dieselfde verband wat tussen die ou tyd en die nuwe tyd is, naamlik die evangelie wat verkondig dat dié wat deur die geloof geregverdig is, sal lewe. Abraham se verhouding tot God was nie anders as die verhouding wat die evangelie van Jesus Christus verkondig nie. Paulus wil een saak baie duidelik stel, onder andere ook deur die uitdrukking Judaiōo te prōton kai Hellēni, en dit is dat die evangelie nie 'n vreemde, totaal ongehoorde, totaal onverwagte daad van God verkondig nie. Net so is die regverdigmaking deur die geloof nie 'n totaal nuwe weg tot saligheid wat God nou eensklaps in Jesus Christus aangekondig het nie. Jood en heiden, Jodedom en kerk staan nie parallel langs mekaar nie maar is konsolidêr teenoor die evangelie as aankondiger van die sōteria (Rom. 1:16) en eirēnē (Rom. 2:9) aan die een kant en die thlipsis en stenoghōria (verdrukking en benoudheid) aan die ander kant (Rom. 2:10).

\section{Kata de tēn eklogēn"2) (Rom. 11:28).}

Die opset van hierdie gedeelte is die antitese. Hier is egter nie 'n saaklike antitese nie, maar 'n retoriese. $\left.{ }^{25}\right)$ Uitverkiesing staan hier nie teenoor die evangelie of selfs selfstandig naas die evangelie nie. Formeel uitgedruk moet eerder gesê word dat die begrip eklogẽ in die kategorie van die begrip euangelion lê. Wat

22) Römerbrief, S. 53.

24) Van die 7 keer wat eklogé in die N.T. voorkom, het Rom. 4 keer.

25) O. Michel, Römerbrief, S. 282. 
dit inhou kan gesien word as die begrip enklogē nagegaan word. Die algemene Griekse betekenis hou altyd in dat die bestes uitgesoek word. ${ }^{26}$ )

In die Romeinebrief kom veral twee aspekte van die begrip na vore. (a) Die opvallendste is dat die algemene Griekse aspek van die bestes uitkies, verval. Dit sien ons al in Rom. 9:11. Voor die geboorte van die twee kinders, voor hulle goed of kwaad gedoen het, kies God. By die verkiesing speel die voorwerp wat verkies word nie die eintlike rol nie, maar God wat roep, (ouk eks ergon all' ek tou kalountos (Rom. 9:12). So is ook die verkiesing tot Christus nie uit die werke nie, maar uit die roeping en ontferming van God. Ook in Rom. 11:6 beklemtoon Paulus dat die verkiesing deur die genade is en nie op grond van die werk nie (sharati, ouketi eksergōn). (b) 'n Tweede opvallende aspek van die begrip in die Romeinebrief is dat die begrip eklogē deur die begrip klētos verklaar word. Die verbintenis tussen hierdie twee begrippe kry ons in Rom. 9:11 en Rom. 11:28-29 waar kletōs parallel en as verklaring van eklogē voorkom. Verkiesing is dus verbonde aan roeping en daarom aan diensbestemming. Hierdie verbintenis tussen uitverkiesing en diensbestemming word uitdruklik gestel in Hand. 9:15.

As ons die begrip klētos in die Romeinebrief nagaan, sal hierdie verbintenis duidelik word. In Rom. 1:1 is die klētos verbind met apostolos - hier het Jesus Christus geroep om uit te stuur. In Rom. 1:7 is die klētos weer verbind met hagios: hier is die roeping onder andere ook met 'n opdrag tot heiligheid verbind.

\section{4. leimma (Rom. 11:5).}

(a) Die bestaan van 'n oorblyfsel het sy grond slegs in die keuse (eklogē) van God uit genade. Die bepalende van die res van die eindtyd is dat hulle deur God se verkiesende genade geroep is.

Omdat die genade die uitverkiesing dra en die res bestem, daarom is die bestaan van die res in die eindtyd teken dat God Israel nie verwerp het nie - al het hulle verhard geword. Die res (oorblyfse) is die "voorwerpe van barmhartigheid" (Rom. 9:23) wat God gekies het as draers van sy heerlikheid.

(b) 'n Enkele opmerking vanuit die begrippe eklogē en leimma. In die Romeinebrief vind ons ,uitverkiesing' nie as 'n tydlose en daarom inhoudlose begrip nie. Uitverkiesing is gawe, (van apostelskap of van heiligheid) maar juis hierom ook opdrag. Die uitverkiesing het die dra en die uitdraii) van God se naam voor oë en

26) T.W.N.T., IV, S. 181

27) Bastadzo (Hand. 9:15) apostolos (Rom. 1:1). 
daarom die eer van God se Naam. Die voorwerpe van eer (eis timēn skeuos Rom. 9:21) is die voorwerpe van barmhartigheid (epi skeuē eleous Rom. 9:23). God skep kruike en vul hulle met 'n heerlike inhoud. Hierdie vul van die kruike is ook opdrag om draers te wees van God se heerlikheid. God se begenadiging is ook sy roeping (Rom. 9:24). Die waarborg dat tot die Godsvolk behoort word, lê nie in die natuurlike toebehoort tot die eiendomsvolk nie, maar in God se genadegawe en opdrag in Jesus Christus. Ook Israel se uitverkiesing bereik alleen in Jesus Christus sy voltooiing. Húlle is die oorblyfsel uit Israel wat die Naam van Jesus Christus bely. Eers dan is Israel by die Vader as hy by Jesus Christus is. Epignōsis (Rom. 10:2) is nie alleen 'n konkrete kennis nie, maar ook belydenis ${ }^{28}$ ) en juis die epignōsis ontbreek by Israel. Die ware kennis bestaan dus ook vir die Jode hierin: „As jy met jou mond die Here Jesus bely en met jou hart glo dat God Hom uit die dode opgewek het, sal jy gered word; want met die hart glo ons tot geregtigheid en met die mond bely ons tot redding (Rom. 10:9 en 10).

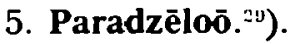

Twee Ou Testamentiese gedagtegange is agtergrond van hierdie begrip.

(a) Die oortreding van Adam (paraptōma) (Rom. 5:5 en 17).

Dit is nie toevallig dat Paulus Adam se oortreding en Israel se oortreding met dieselfde begrip aandui nie. Adam se oortreding het in een daad van ongehoorsaamheid bestaan. So bestaan Israel se oortreding in die een daad van verwerping van die geloof as weg tot redding en die oprigting van hulle eie geregtigheid (Rom. 10:2). Paulus wil liewer dat hulle jaloers gemaak sal word (paradzèloō) as wat hulle 'n (nuttelose) ywer het sonder kennis (dzelon Theou echousin, all'ou' kat epignōsin, Rom. 10:2). Soos wat die oortreding van Adam verreikende gevolge gehad het, (Rom. 5:12, 15, 17) so het ook die oortreding van Israel wêreldwye gevolg (ploutos kosmou, Rom. 11:12).

(b) Deut. 32:21 en Jes. 65:1:

Ons vind die jaloersmaak van Israel in die Godspraak van Deut. 32:21 (Rom. 10:19). Omdat Israel 'n nie-God aanbid het, sal God Israel jaloers maak deur Hom by 'n nie-volk te skaar, terwyl Hy Hom vir Israel verberg. God sal dit doen om Israel op sy dwaalweg opmerksaam te maak. Dit is dan nou die weg van God met Israel. Terwyl Hy Hom in sy toorn vir Israel verberg, openbaar $\mathrm{Hy}$ Hom in die midde van die heidendom. Dit doen God om Israel jaloers te maak. Deur die verkondiging dat die

28) Michel, Römerbrief, S. 254.

20) Rom. 10:19; 11:11; 11:14. 
gemeente van Jesus Christus nou die ware volk van God is, word Israel jaloers gemaak, 'n jaloersmaking wat tot Israel se bekering wil lei. So is Paulus self deur die heidensending geroep om Israel jaloers te maak, om hulle diep onrustig ${ }^{30}$ ) te maak (Rom. 11:14).

\section{Die verhouding tussen Israel en kerk.}

Dit lê voor die hand dat Israel ook aan kerk aanstoot sou neem en die kerk sou toesnou: nie-volk en dwase-volk (ep ouk ethnei/ep ethnei asunetō (Rom. 10:19). Teenoor hierdie wettige beskuldiging van Israel antwoord die Godspraak egter: „Ek het My laat vind deur die wat My nie gesoek het nie; Ek het verskyn aan die wat na My nie gevra het nie" (Rom. 10:20).

Teenoor Israel kan die kerk sê: „God het aan ons verskyn” en dan teenoor Israel roem (katakauchaomai Rom. 11:18). Vir die Christen wat roem sê Paulus: „Moenie hoogmoedig wees nie, maar vrees" (Rom. 11:20).

\section{Die verharding van Israel (pōrōsis).}

(a) God verhard.

Net soos die verkiesing daad van God se vrye genade is, so is ook die verharding God se daad. Is hierdie haat (emisēsa, aur.!, Rom. 9:13) van God nie onregverdig nie? K. Barth ${ }^{31}$ ) het daarop gewys dat hierdie verkiesing en verstoting nie op God se naakte souwereine reg berus nie. Hierdie geregtigheid is die geregtigheid van die goddelike barmhartigheid (Rom. 9:15). Beide geliefde en gehate het geen aanspraak teenoor God nie, want $\mathrm{Hy}$ het beide bestem vir sy doel (Rom. 9:17).

So verhard God ook nou Israel epōrōthēsan - die pass. (Rom. 11:7) wys dat God handel, net soos Farao, sodat ook in die krag van God se barmhartigheid openbaar kan word en dat sy Naam verkondig kan word op die hele aarde.

(b) Waarteen is die verharding?

Die verharding bestaan in die ongehoorsaamheid teen die Woord van God. So was dit by Farao en so is dit ook by Israel. Israel het hom gestamp teen die steen van aanstoot (Rom. 9:32). Hulle wil hulle aan die geregtigheid van God nie onderwerp nie - hulle wil nie erken (all' ou kat' epignōsin Rom. 10:2) dat Christus die einde van die wet is tot geregtigheid vir elkeen wat glo nie.

(c) Het God sy volk van Hom af ${ }^{32}$ ) weggestoot? (Rom. 11:1).

30) O. Michel, Römerbrief, S. 264.

31) Kurze Erklärung, S. 141.

32) Aposato, aur, med. Die med. wil ons die intense betrokkenheid van die subjek uitdruk. 
(i) Ons het alreeds gesien dat Paulus self en die bestaan van die oorblyfsel (leimma) teken is dat God nie sy volk van Hom af weggestoot het nie.

(ii) Die verharding het net ten dele oor Israel gekom - God het aan die verharding 'n perk gestel (Rom. 11:25).

(iii) God het sy volk nie van Hom af weggestoot nie omdat die genadegawe en die roeping van God onberoulik is (Rom. 11:29).

(d) Deur Israel se oortreding het die redding tot die heidene gekom .

Paulus stel dit telkens dat deur Israel se oortreding die redding tot die heidene gekom het (Rom. 11:11). Hulle val is die rykdom van die wêreld (Rom. 12:12). Die takke van die mak olyfboom is afgebreek sodat dié van die wilde olyfboom ingeënt kon word (Rom. 11:17). Die ongehoorsaamheid van Israel is die weg van God tot barmhartigheid oor die heidene (Rom. 11:30).

Skynbaar lyk dit dus of die kerk wanneer hy te staan kom voor die verharding van Israel voor 'n onoorbrugbare probleem en voor 'n onoorkombare verleentheid te staan kom. Paulus wil egter dat ons die oog op Christus se dunamis sal vestig. Teenoor die verharding van Israel staan Christus en sy dinamiek van Woord en Gees. In Christus het Israel 'n verlede en toekoms 'n verlede waarin die geloof is en begenadig en uitverkies is op grond van die geregtigheid wat uit die geloof is en 'n toekoms wat in Jesus Christus reeds werklikheid geword het. God is deur die barmhartigheid aan die heidene op pad na Israel. Die klem val nooit op die mens en sy verharding nie, maar op die triomferende werke van God (Rom. 11:33-36).

\section{DIE „WEG” VAN DIE KERK MET ISRAEL?}

(a) Hierdie vraagstelling sal eers dan beantwoord kan word as tenvolle erns gemaak is met die kennis dat God op weg is met Israel. Dit word telkens duidelik, maar veral as ons die begrippe eklogē en paradzeloō saamlees. Israel sal jaloers gemaak word omdat God deur die uitverkiesing sy heerlikheid in die kerk openbaar het. Die kerk sal Israel jaloers maak as hy hierdie heerlikheid aan die heidene en aan Israel verkondig.

(b) In sy verkondiging aan Israel staan die kerk egter in 'n besondere verhouding tot Israel. Dit is nie 'n nuwe evangelie wat Israel nou eers hoor nie. Die regverdigmaking deur die geloof in Jesus Christus is nog altyd aan Israel openbaar. By die verkondiging aan Israel is dit nie 'n saak van ",nog nie gehoor nie", maar saak van "nog nie gehoorsaam nie” (Rom. 10:16, 18, 19).

33) K. Barth, Kurze Erklärung, S. 135. 
(c) Die evangelie vra volle voorbehoudlose solidariteit van die gehoorsames met die ongehoorsames. Hierdie solidariteit sal meebring dat die verharding van Israel vir ons ,'n groot droefheid en 'n onophoudelike smart vir my hart" sal wees (Rom. 9:2). Oorsprong van hierdie droefheid is geen volksgevoel en menslikheidsgevoel nie, maar die getuienis van die Heilige Gees. Hierdie verlange van die hart sal gebed word (Rom. 10:1). Maar juis hierom sal hierdie solidariteit in die verkondiging van die evangelie gestalte kry. „Die weg van die kerk met Israel van die verharding blyk dan die weg van die verkondiging van Jesus Christus (1 Pet. 2:9 en 10) te wees . . " ${ }^{34}$ )

34) C. J. Mans, Rondom Kerk en Israel, bl. 83. 